Fixed Point Theory, 22(2021), No. 1, 343-358

DOI: $10.24193 /$ fpt-ro.2021.1.24

http://www.math.ubbcluj.ro/ nodeacj/sfptcj.html

\title{
INTERSECTION OF NONEXPANSIVE MAPPINGS WITH RESPECT TO A FINITE NUMBER OF RENORMINGS
}

\author{
JUAN RAFAEL ACOSTA-PORTILLA \\ Facultad de Economía, Universidad Veracruzana, México \\ E-mail: juaacosta@uv.mx
}

\begin{abstract}
Given a Banach space $(X,\|\cdot\|)$ and a subset $C$ of $X$, we consider the family of bounded Lipschitzian mappings $B \operatorname{Lip}(C, X)$. This family is endowed with a norm and a topology that does not depend on renormings. With this topology we prove that it is not enough to consider the family of mappings that are nonexpansive with respect to finitely many renormings, to get the family of mappings that are nonexpansive w.r.t. all renormings.
\end{abstract}

Key Words and Phrases: Fixed point, renorming, nonexpansive mapping, affine mapping, meager set, Baire's category theorem.

2020 Mathematics Subject Classification: 46B20, 46T99, 47H09, 47H10.

Acknowledgment. The author would like to thank the referees for their valuable comments. The author was partially financed by CONACyT National Grant 415270

\section{REFERENCES}

[1] J.R. Acosta-Portilla, C.A. De la Cruz-Reyes, C.A. Hernández-Linares, V. Pérez-García, Lipschitzian mappings under renormings, J. Nonlinear Convex Anal., 20(10)(2019), 2239-2257.

[2] J.R. Acosta-Portilla, C.A. Hernández Linares, V. Pérez García, About some families of nonexpansive mappings with respect to renorming, J. Funct. Spaces, 2016, art. ID 9310515: 9 pages, 2016.

[3] A. Barrera-Cuevas, M.A. Japón, New families of nonreflexive Banach spaces with the fixed point property, J. Math. Anal. Appl., 425(2015), no. 1, 349-363.

[4] T. Domínguez Benavides, A renorming of some nonseparable Banach spaces with the fixed point property, J. Math. Anal. Appl., 2(350)(2009), 525-530.

[5] T. Domínguez Benavides, S. Phothi, Porosity of the fixed point property under renorming, Fixed Point Theory and its Applications, 29-41, Yokohama Publ., Yokohama, 2008.

[6] T. Domínguez Benavides, S. Phothi, The fixed point property under renorming in some classes of Banach spaces, Nonlinear Anal., 72(2010)(3-4), 1409-1416.

[7] T. Domínguez Benavides, S. Phothi, Genericity of the fixed point property for reflexive spaces under renormings, Nonlinear Analysis and Optimization I. Nonlinear Analysis, Contemp. Math. 513, pages 143-155, Amer. Math. Soc., Providence, RI, 2010.

[8] T. Domínguez Benavides, S. Phothi, Genericity of the fixed point property under renorming in some classes of Banach spaces, Fixed Point Theory and its Applications, pages 55-69, Yokohama Publ., Yokohama, 2010.

[9] H. Fetter, B. Gamboa-de Buen, Banach spaces with a basis that are hereditarily asymptotically isometric to $l_{1}$ and the fixed point property, Nonlinear Anal., 71(10)(2009), 4598-4608. 
[10] B. Gamboa-de Buen, F. Núñez-Medina, A generalization of a renorming theorem by Lin and a new nonreflexive space with the fixed point property which is nonisomorphic to $l_{1}$, J. Math. Anal. Appl., 405(2013), no. 1, 57-70.

[11] C.A. Hernández-Linares, M.A. Japón, A renorming in some Banach spaces with applications to fixed point theory, J. Funct. Anal., 258(10)(2010), 3452-3468.

[12] C.A. Hernández-Linares, M.A. Japón, Rays of equivalent norms with the fixed point property in some nonreflexive Banach spaces, J. Nonlinear Convex Anal., 15(2)(2014), 355-357.

[13] C.A. Hernández-Linares, M.A. Japón, E. Llorens-Fuster, On the structure of the set of equivalent norms on $\ell_{1}$ with the fixed point property, J. Math. Anal. Appl., 2(387)(2012).

[14] Pei-Kee Lin, There is an equivalent norm on $l_{1}$ that has the fixed point property, Nonlinear Anal., 68(8)(2008), 2303-2308.

[15] Pei-Kee Lin, Renorming of $\ell_{1}$ and the fixed point property, J. Math. Anal. Appl., 363(2)(2010), 534-541.

[16] N. Weaver, Lipschitz Algebras, World Scientific, 2018.

Received: November 8, 2018; Accepted: October 31, 2019. 